\title{
СОВЕРШЕНСТВОВАНИЕ ПРОЦЕССА ФОРМИРОВАНИЯ ИСТОЧНИКОВ ФИНАНСИРОВАНИЯ И ИСПОЛЬЗОВАНИЯ СРЕДСТВ ПЕНСИОННОГО ФОНДА РФ
}

\author{
(c) 2019 Серпер Евгений Александрович \\ доктор экономических наук \\ Самарский государственный экономический университет, Россия, Самара \\ E-mail: fikr@bk.ru
}

В научной статье рассматриваются проблемы формирования источников средств Пенсионного фонда России и пути их решения.

Ключевые слова: Пенсионный фонд, внебюджетные фонды, доходы, расходы, бюджет, дефицит бюджета, безвозмездные поступления.

В последнее время остро стоят вопросы проведения пенсионной реформы в Российской Федерации. Авторы предлагают возможные подходы к решению этой задачи.

Принимая во внимание и то, что размер пенсионного обеспечения, разных видов социальных выплат невелики по отношению к странам Запада можно сказать, что Пенсионный фонд терпит сильный недостаток денежных средств.

Основная причина возникновения недостатка средств кроется не в деятельности фонда, а в экономике страны в целом. Сильное влияние оказывает теневая экономика страны, которая избегает полноразмерной уплаты страховых взносов.

По данным Всемирного банка на конец 2017 года объем теневой экономики в Российской федерации составляет около $43 \%$ от ВВП страны. В то же время в Китае этот показатель находится на уровне $13 \%$, в США 9\%, в Швейцарии $8 \%$, а в Израиле 6,6\%.

Теневая экономика влияет тем, что не регистрирует свои доходы и не уплачивает от них налоги, сборы и страховые взносы.

По данным Федеральной службы по труду и занятости около $11 \%$ населения страны получают всю свою зарплату «в конверте», без оформления по месту работы и не платят взносы в Пенсионный фонд. Помимо этого, около 15-16\% граждан получают нелегальную зарплату частично, что тоже сокращает размер страховых взносов.

Рассчитаем сколько средств не уплачивается в Пенсионный фонд. Для этого нам нужно знать среднюю заработную плату в 2017 году и количество занятых граждан. По данным Росстата в 2017 году средняя заработная плата составляла приблизительно 35369 рублей. В среднем за год было занято 71,9 млн. граждан. От суммы доходов в фонд уплачивается 22\%. Исходя из этого можно рассчитать сумму, которая должна была поступить в фонд в 2014 году: 5,5946 млрд. рублей. Стоит заметить, что в расчетах не учтены льготы и дополнительные условия, которые могут уменьшить конечный объем поступлений. Однако если сравнить это число с доходами фонда в 2017 году, то становится видно, что не уплачиваются огромные средства.

Таким образом, даже принимая во внимание то, что расчеты носят приблизительный характер и не учитывают многие особенности можно сказать, что фонд из-за сильного распространения теневой экономики недополучает большие средства, которые могли бы не только избавить его от дефицита бюджета, но и снизить нагрузку на федеральный бюджет, который каждый год поддерживает работу фонда.

Из сказанного выше следует, что первостепенная задача должна быть в снижении доли теневой экономики в стране.

Обычно под теневой экономикой понимают «всю текущую незарегистрированную экономическую деятельность, которая входит в официальный расчетный ВВП».

Ф. Смит определяет это понятие как «рыночное производство товаров и услуг, законных или незаконных, что избежало обнаружения в официальных оценках ВВП».

Некоторые аналитики указывают в роли основной проблемы вопрос с демографией в стране. Так как основное назначение фонда - это социальная поддержка нетрудоспособного населения и пенсионеров, то огромное значение имеет число пенсионеров. А также, из-за того, 
что основные средства должны поступать из страховых взносов от доходов населения, важным является количество занятого населения и его отношение к количеству пенсионеров. Помимо этого, важным показателем будет количество работающих пенсионеров (Табл.1).

Из таблицы видно, что численность пенсионеров, как и численность занятых в стране растет. Однако наибольшую важность представляет отношение числа работающих граждан к числу пенсионеров (Рис. 1).

Из графика видно, что одного пенсионера в 2012 году приходилось 1,78 занятых граждан, но к 2016 году этот показатель сократился до 1,69.
На практике это означает, что одного пенсионера обеспечивает меньше двух работающих человек. Для сравнения в Японии этот показатель близок к 3 работающим гражданам на одного пенсионера.

Так же необходимо учитывать тот факт, что среди работающих людей могут быть и пенсионеры, страховые взносы с зарплаты которых так же идут на содержание пенсионеров.

Рассмотрим на графике, какая доля пенсионеров работает и получает пенсию (Рис. 2).

На графике видно, что в исследуемом периоде доля работающих пенсионеров близка к 32\% от числа пенсионеров в 2016 году, а в 2015 она

Таблица 1. Статистика по количеству работающих граждан в стране и количеству пенсионеров (тыс. чел.) [1]

\begin{tabular}{|l|c|c|c|c|c|}
\hline & 2012 & 2013 & 2014 & 2015 & 2016 \\
\hline Число занятых в России & 71545,4 & 71391,5 & 71539 & 72324 & 72393 \\
\hline Численность пенсионеров & 40162 & 40573 & 41019 & 41456 & 42729 \\
\hline Из них работающих пенсионеров & 13030 & 13669 & 14325 & 14917 & 15259 \\
\hline
\end{tabular}

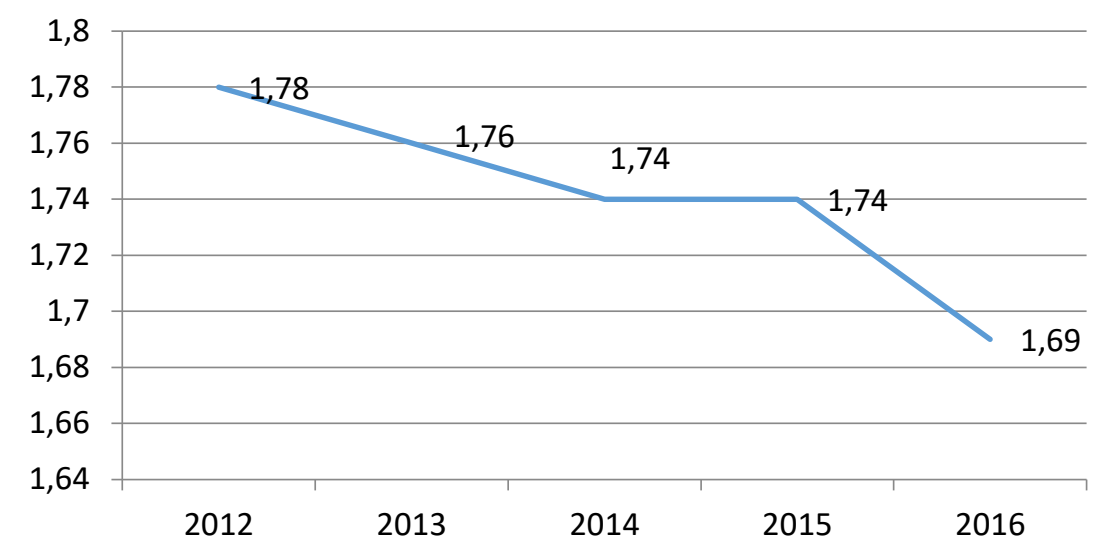

Puc. 1. Динамика количества занятых граждан на одного пенсионера [1]

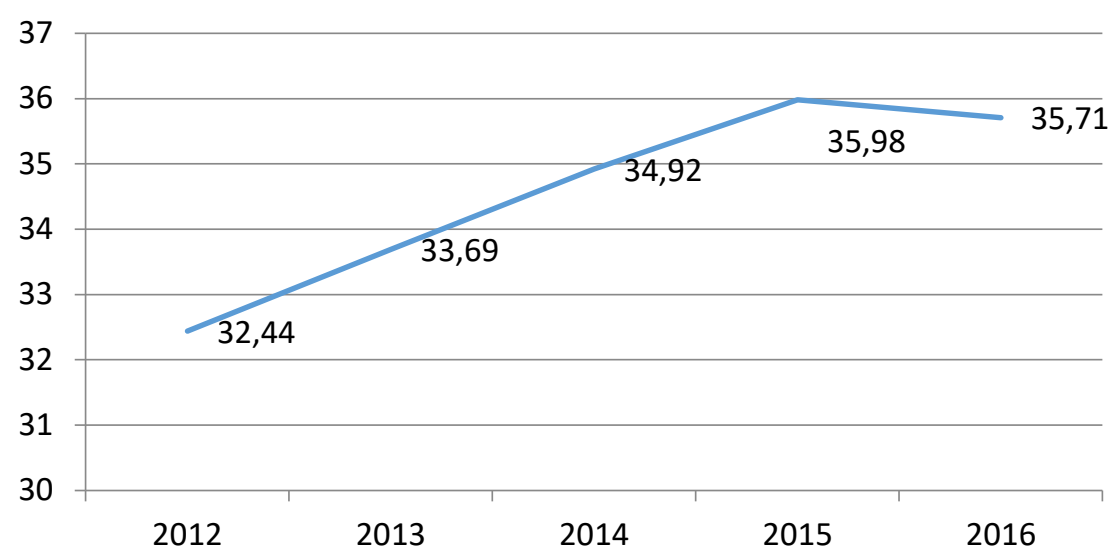

Puc. 2. График изменения доли работающих пенсионеров в общем количестве пенсионеров в России [1] 
составила почти 36\%. Для сравнения в 2001 году она была близка к $16 \%$.

Это свидетельствует о том, что пенсионерам недостаточно средств, получаемых в рамках пенсионного обеспечения, а также о том, что число таких пенсионеров увеличивается из года в год.

Так же стоит обратить внимание на то, какую долю занимают работающие пенсионеры в числе всех занятых граждан в стране (Рис. 3).

График показывает, что за исследуемый период, доля пенсионеров в занятом населении страны составляла $18,21 \%$ в 2012 году и увеличилась до 21,08\% в 2016 году. Аналогичная динамика была от 2001 года $(9,4 \%)$ к 2009 году $(15,8 \%)$.

Можно сказать, что пятая часть работающих в 2017 году - пенсионеры. Что еще раз подтверждает вывод о том, что пенсионного обеспечения в стране недостаточно. Помимо этого, данные говорят о том, что $1 / 5$ часть работающих перестанут работать в тот момент, когда пенсионное обеспечение в стране повысится.

Если вспомнить расчет суммы средств, которые должен был получить Пенсионный фонд в случае уплаты всех страховых взносов, то можно сказать, что даже 1,7 занятых граждан на 1 пенсионера вполне достаточно, чтобы обеспечивать работу пенсионного фонда даже без большой помощи федерального бюджета. Однако если учесть, что $1 / 5$ часть занятых граждан - пенсионеры, а пенсионное обеспечение в стране недостаточное, то можно сказать что соотношение 1,7 занятых граждан к 1 пенсионеру слишком низкое для работы фонда в нормальных условиях. Тем более, что при увеличении пенсионного обеспечения число работающих пенсионеров будет сокращаться, что приведет к еще большему снижению этого отношения. Например, если все работающие пенсионеры перестанут работать, то на одного пенсионера будет приходиться 1,39 занятых граждан [2].

Причиной возникновения демографической проблемы могут служить такие факторы как:

- Изменение средней продолжительности жизни в стране

- Изменение динамики прироста населения

Рассмотрев динамику средней продолжительности жизни в стране за последние 20 лет, можно сделать вывод, что с момента образования Пенсионного фонда произошел резкий спад средней продолжительности жизни населения, который вернулся в исходное значение только к 2009-2010 годам.

Для понимания, почему происходит увеличение нагрузки на Пенсионный фонд необходимо рассмотреть период с 2000 по 2017 года. Если в 2000 году средняя продолжительность жизни составляла 65,3 года, то в 2017 году 72,4 года. С одной стороны, это говорит об улучшении здравоохранении и социального обеспечения граждан, а также общих условиях жизни, с другой сильно увеличивает нагрузку на фонд, так как количество пенсионеров увеличивается с каждым годом.

Если взять за начало анализа 2000 год, то необходимо смотреть на уровень рождаемости 1978-1980x годов. Таким образом, в 2000 году начинается рост продолжительности жизни населения, как и рождаемость 20 лет назад, которая в конце 80x годов достигла своего пика. Однако дальше можно наблюдать резкое снижение рождаемости в период с 1988 по 1993 год. Этот

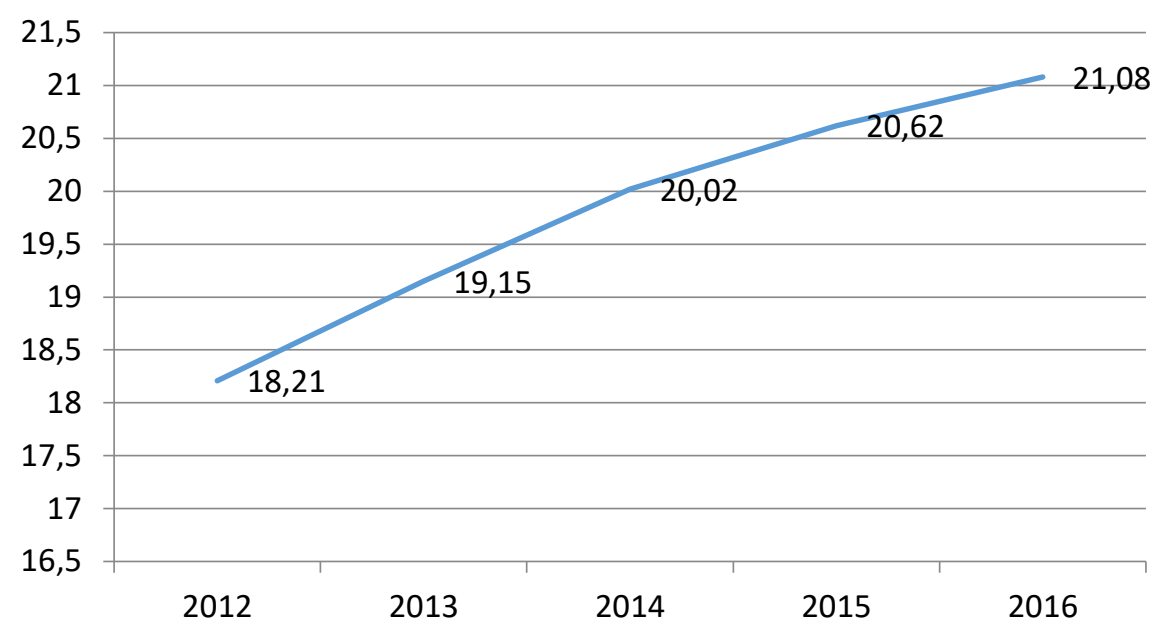

Puc. 3. Доля пенсионеров в занятом населении страны [1] 
резкий спад рождаемости проявит себя через 20 лет в промежутке с 2008 по 2013 года, в тот момент, когда средняя продолжительность жизни населения вырастет, а рождаемость в период 20ти летней давности уменьшит потенциальное количество занятого населения.

С 2000 года по 2016 средняя продолжительность жизни населения увеличилась на 9,5\%, когда в период с 1987 по 1994 года произошел спад рождаемости почти на $43,7 \%$, такая сильная разница в динамике оказывает сильное влияние на бюджет Пенсионного фонда в эти периоды [4].

Кроме исследования влияния демографических показателей в прошлых годах, можно также прогнозировать это влияние на будущие периоды. Например, можно сказать, что спад рождаемости в 1994 году продолжился до 2000 года, что усугубит существующую ситуацию в ближайшие 5-7 лет, однако с 2000 года начинается рост рождаемости, что говорит о снижении влияния этого фактора после 2020 года.

В процессе анализа было выявлено две основные проблемы, из-за которых Пенсионный фонд не может полностью за счет своих средств выполнять поставленные перед ним задачи.

Первая проблема - большая доля теневой экономики в стране. На данный момент государство пытается ограничить и вытеснить теневой рынок двумя путями. Первый основан на экономических мерах, назначение которых сделать для предпринимателей участие в легальных, официальных рыночных отношениях экономически и материально более выгодным и безопасным, чем иметь дело с рынком нелегальным, теневым. Второй - включает меры государственного принуждения, а именно совершенствование законодательства, направленного на усиление борьбы с участниками теневого рынка, и обеспечение неуклонного проведения его в жизнь. При этом обсуждается возможность использования еще и третьего пути, успешно апробированного в некоторых государствах с ныне развитой экономикой, но находившейся ранее в кризисе: объявление своего рода амнистии для нарушающих закон предпринимателей.

Выделяют два основных пути легализации теневого капитала. Главным их них является демократизация всех сторон социально-экономических отношений, создание благоприятных для производителя правовых условий, реформа налоговой системы, реальная ответственность исполнительных органов перед парламентом, изменение денежной и валютной политики. Но эти меры требуют очень серьезной политической воли государства. Видимо, для эффективного и всестороннего решения проблемы следует идти по пути легализации теневого капитала, не прекращая борьбы с его криминальными проявлениями. Это определяется тем, что в руках предпринимателей в теневом рынке накапливаются огромные средства, которые могут быть превращены в реальные инвестиции. По предварительной оценке специалистов, общий объем таких инвестиций в России мог бы составить около 500 млрд. долл.

Вторая проблема - демографическая. Количество пенсионеров по отношению к занятому населению велико и продолжает расти.

Для решения демографической проблемы в краткосрочном периоде существует не так много методов.

Основной метод - увеличение пенсионного возраста. Если граждане будут выходить на пенсию позже, то необходимо будет меньше средств на их обеспечение и одновременно они должны будут дольше работать, что принесет дополнительный доход в Пенсионный фонд. Однако использование этого метода может привести к недовольству населения или более серьезным социальным последствиям.

Второй способ нейтрализовать проблему нехватки занятого населения - повышение страховых взносов. Однако этот способ может не принести нужного результата, потому что вместо роста страховых взносов может произойти увеличение доли теневой экономики в стране, которая, как говорилось выше, и так занимает около $40 \%$. Также этот метод может вызвать дополнительные побочные эффекты:

- снижение темпов роста экономики;

- сокращение малого и среднего бизнеса;

- снижение уровня жизни граждан и т.д

Отдельно стоит упомянуть решение правительства перечислить накопительную часть средств фонда в страховую. То есть из $22 \%$ страхового взноса от дохода гражданина 6\% будет, как и прежде, направляться на солидарную часть пенсии, $10 \%$ будут направляться на страховую часть пенсии, а последние 6\% будут направляться в зависимости от желания граждан. Существует 2 варианта:

1. Перечислять средства в негосударственный пенсионный фонд в накопительную часть пенсии; 
2. Оставить средства в Пенсионном фонде России, где они будут зачисляться в дополнение к 10\% в страховую часть пенсии.

Помимо этого, все, кто не изъявил желания переводить средства в негосударственный пенсионный фонд, автоматически оставляют их в Пенсионном фонде России и перечисляют в страховую часть пенсии. Это изменение привело к тому, что фонд может больше средств направлять именно на социальное обеспечение граждан, а не инвестировать их для формирования накопительной части пенсии в будущем.

Современное законодательство ограничивает круг активов, разрешенных для размещения накопительной части пенсии.

С одной стороны, такое ограничение снижает риски, связанные с инвестированием денежных средств, а с другой - не позволяет получать высокую прибыль от инвестирования свободных денежных средств.

Таким образом, с одной стороны отказ от накопительной части пенсии лишает возможность Пенсионного фонда вкладывать средства, с другой стороны фонд не мог инвестировать средства в высокодоходные объекты в целях безопасности, поэтому доходы от инвестирования средств были незначительными в общей структуре доходов фонда.

Третий вариант улучшения финансовой ситуации фонда - временный отказ от индексации пенсии. Эффект от этого решения будет незамедлительным, но он временный и имеет ряд неблагоприятных последствий, поэтому рассчитывать на него стоит в случае временной необходимости средств с последующей реформой. Отрицательные эффекты могут быть выражены B:

- снижении уровня жизни населения;

- снижении покупательной способности;

- падении темпов роста экономики;

- росте уровня бедности населения и т.д.

В 2014 году Правительство приняло решение изменить условия индексации пенсий. Было введено условие, которое отменяет индексацию пенсии на тот период, пока пенсионер продолжает работать. Это позволило сэкономить некоторую часть средств, выделяемых на индексацию пенсий, особенно учитывая тот факт, что в 2017 году были официально трудоустроены 35\% пенсионеров. В общем итоге это решение может вызвать несколько последствий, в том числе их совокупность:
1. Снижение доли работающих пенсионеров, что в свою очередь снизит страховые поступления в Пенсионный фонд;

2. Снижение доли официально трудоустроенных пенсионеров, что приведет к снижению страховых поступлений в фонд и росту теневой экономики;

3. Снижение расходов на индексацию пенсий.

Помимо решения приостановить индексацию пенсии работающим пенсионерам в Правительстве рассматривался законопроект, в котором пенсионерам, зарабатывающим более 1 млн. рублей в год будет приостановлена выплата пенсий. Это решение может привести к экономии около 17 млрд. рублей в год, по оценкам экспертов.

На наш взгляд, необходимо изменить систему налогообложения, в первую очередь ввести прогрессивную шкалу налога. Это будет способствовать восстановлению справедливости и существенно увеличит бюджет страны, в том числе и ПФР. Следует продолжать поддерживать малый и средний бизнес путем предоставления ему разного рода налоговых льгот.

Не мешало бы руководству страны подумать об установлении твердых нормативов соотношения минимальной и максимальной пенсий в пределах допустимого.

К 2017 году Пенсионный Фонд России перешел к единому информационному пространству внутри фонда. Это даст ему эффективность с точки зрения экономии ресурсов - человеческих, финансовых, энергетических, а также с точки зрения гибкости, так как задачи усложняются, законы часто меняются, и информации становится все больше.

Если обобщить все вышесказанное можно сделать несколько выводов.

Без серьезных изменений в политике государства в пенсионном фонде будет продолжаться серьезный дефицит средств, получаемых от страховых взносов. Однако резкие изменения в пенсионной системе могут привести к серьезным побочным эффектам социального и экономического характера. К тому же эти изменения на фоне общей экономической ситуации в стране могут не принести необходимого эффекта.

Демографическая составляющая тоже имеет свою роль в будущем пенсионной системы, так как с каждым годом количество пенсионеров в отношении к занятому населению растет, что не 
может не сказаться на функционировании всей системы, а также этот фактор будет все больше влиять с течением времени, и будет заставлять все быстрее принимать какие-либо меры по стабилизации.

Рассмотренные выше проблемы и недостатки действующей пенсионной системы являются препятствием для ее успешного поступательного развития. Этот комплекс сформировался под влиянием многочисленных социальных, политических, демографических и исторических факторов, и его разрешение возможно лишь путем сочетания сонаправленных мер социально-экономической политики государства. В соответствии с отмеченными недостатками, предлагаем оценить возможные способы их преодоления. Первая группа потенциальных мер, направленных на формирование накопленного объема реального пенсионного капитала, предполагает собой следующие направления его увеличения.

1. Повышение тарифа пенсионных взносов с целью компенсировать сокращение базы для уплаты этих взносов. Безусловно, последуюшее повышение тарифов пенсионных взносов будет иметь отрицательные общеэкономические последствия. Перманентное повышение тарифа ставит под угрозу конкурентоспособность российской экономики, и в условиях высокой эластичности заработной платы и терпимости населения к неформальным формам трудовых отношений приведет к расширению зоны неформальной и теневой занятости. Более привлекательным представляется перераспределение бремени страховых взносов между работодателями и работниками. Несмотря на то, что с экономической точки зрения такое перераспределение ничего не меняет, введение отчислений в пенсионную систему с заработков работников может повысить их ответственность по формированию собственных пенсионных прав и пенсионных накоплений. Однако следует отметить, что возможности работника воздействовать на форму трудовых отношений в значительной степени ограничены.

2. Увеличение доли бюджетного финансирования пенсионной системы. Целесообразность данного решения зависит от того, какие цели оно будет преследовать, и какие источники финансирования будут использованы. В настоящее время доля бюджетных средств в финан- сировании российской пенсионной системы высока по меркам развитых стран. Кроме того, усиление бюджетной зависимости пенсионной системы противоречит ее страховому характеру (что подразумевает преимущественную опору на поступления страховых взносов). А это, в свою очередь, это усиливает политическую зависимость пенсионной системы от ситуации с федеральным бюджетом, поскольку в условиях бюджетного дефицита пенсионные расходы могут быть снижены.

3. Повторное разделение базовой и страховой частей пенсии между собой, а также по условиям назначения, правилам индексации и источникам финансирования. Базовая и страховая части пенсии относятся к разным уровням пенсионного обеспечения и направлены на решение различных задач. Задачей базовой части пенсии является борьба с бедностью пенсионеров и обеспечение перераспределения внутри пенсионной системы с целью, а также сглаживания существующее на рынке труда неравенство. Задача страховой части пенсии заключается в компенсации утраченного заработка, обеспечении связи размера пенсии с прежним страховым вкладом человека. Страховая часть пенсии в меньшей степени служит задачам перераспределения, а в большей - отвечает интересам средних слоев населения. Неравенство в заработках вынуждает пенсионную систему сохранять универсальную компоненту, не зависящую от трудового вклада человека.

Таким образом, можно утверждать, что необходимость реформирования пенсионной системы в России выходит далеко за рамки обеспечения способности государства выплачивать своим гражданам достойную пенсию. Не сводится она и к совершенствованию финансовых рынков РФ.

Эффективное решение проблемы возможно лишь, на наш взгляд, на основе синергизма системы социально-политических, макроэкономических, демографических и организационно-правовых решений, которые помимо социального и экономического эффекта будут способствовать установлению консенсуса между государством, гражданами и бизнесом по вопросам построения эффективной пенсионной системы, которое, в конечном итоге, представляется возможным только при достижении компромисса между всеми сторонами. 


\section{Библиографический список}

1. Федеральная служба государственной статистики: Официальный сайт. Режим доступа: http://www.gks.ru/ wps/wcm/connect/rosstat

2. Пенсионный фонд Российской Федерации Официальный сайт. Режим доступа: http://www.pfrf.ru/

3. Финансы и кредит: учебник/ коллектив авторов; под ред. проф. Т.М. Ковалевой.-9-е изд., перераб. и доп. Москва: КНОРУС, 2018.

4. Современное состояние государственных, муниципальных финансов в Российской Федерации/ Монография/ под ред. проф. Т.М. Ковалевой. СПб.: Изд-во Политехн. ун-та, 2018. - 245 с. 